\title{
Short Communication \\ Shape changes in isolated outer hair cells: measurements with attached microspheres
}

\author{
Gary Zajic and Jochen Schacht \\ Kresge Hearing Research Institute, The University of Michigan, Ann Arbor, Michigan, U.S.A.
}

(Received 6 September 1990; accepted 10 November 1990)

\begin{abstract}
Shape changes can be induced in isolated outer hair cells by various stimuli and quantified from digitized video-images. While overall changes in length between base and apex are easily measured, changes in defined segments of the cell require fixed landmarks on the cell body. The problem of locating such landmarks makes it difficult to assess if a change in length is uniform or largely confined to a particular segment of the cell. This information is important in identifying the location of a contractile apparatus and the elucidation of mechanisms of motility. We demonstrate here that microspheres can serve as reference points for such measurements.

By attaching microspheres to cells we determined that, when outer hair cells increased their volume upon $\mathrm{K}^{+}$-depolarization, their middle scgment shortened more significantly $(14 \pm 6 \%)$ than either the basal $(10 \pm 5 \%)$ or apical section $(7 \pm 6 \% ; P<0.01)$. In contrast, when cortical contractions were induced by elevating intracellular $\mathrm{Ca}^{2+}$, the elongation of the cells was more pronounced in their basal $(8 \pm 2 \%)$ than their apical $(6 \pm 2 \% ; P=0.06)$ or middle region $(6 \pm 3 \%)$. This study provides further insight into the mechanisms of shape changes in isolated outer hair cells and illustrates a method to analyze localized changes in the absence of internal landmarks.
\end{abstract}

Outer hair cells; Motility; Calcium; Potassium Depolarization; Microspheres

\section{Introduction}

Shape changes in response to various chemical and physiological stimuli have been well documented in isolated outer hair cells (Goldstein and Mizukoshi, 1967; Brownell et al., 1985; Zenner et al., 1985; Dulon et al., 1988; Slepecky et al., 1988; Dulon et al., 1990) as well as in inner hair cells (Dulon et al., in press). While overall changes in length, i.e. from base to apex of the cell, and changes in diameter have been reported, little is known as to whether the observed contractions or elongations are uniform along the cell axis or confined to certain segments of the cell. Such information could shed light on the localization of the contractile apparatus and help in clucidating mechanisms of hair cell motility. Holley and

Correspondence to: Jochen Schacht, Kresge Hearing Research Institute, The University of Michigan, Ann Arbor, MI 481090506, U.S.A.
Ashmore (1988) addressed this question for electrically induced contractions by measuring displacement of discrete cellular organelles. They pointed out that a potential problem in their method was the uncertainty as to whether or not the movement of selected particles was independent of movements of the plasma membrane or other cellular structures.

In this study we present a method to measure differential shape changes along the hair cell body. Small ion exchange resin beads have been used to solve a similar question in the movement of muscle (Warshaw et al., 1987). Here we report the use of microspheres as fixed reference points to determine shape changes in segments of isolated outer hair cells.

\section{Methods}

\section{Hair cell isolation}

The organ of Corti was dissected from the cochlea of pigmented guinea pigs in Hanks' Bal- 
anced Salt Solution (HBSS, buffered to $\mathrm{pH} 7.4$ with $5 \mathrm{mM}$ sodium HEPES and adjusted to $300 \pm 1$ mOsm with $\mathrm{NaCl}$ ), and outer hair cells were isolated as previously described (Brownell et al., 1985; Zajic and Schacht, 1987). Briefly, segments of the organ of Corti were transferred with a microsyringe (Hamilton No. 705) to 50- $\mu 1$ droplets of HBSS containing $0.5 \mathrm{mg}$ of collagenase (type IV, Sigma, St. Louis, MO)/ml HBSS. After a 15 -min incubation at room temperature, the segments were transferred into $50 \mu 1$ of collagenase-free HBSS and dissociation was completed by gentle flux and efflux of the pieces of organ of Corti through the microsyringe. All procedures were carried out in a humid chamber in order to avoid evaporation and changes in the osmolality of the solutions.

\section{Measurement of hair cell dimensions}

Fluorescent (conjugated to fluorescein) and non-fluorescent microbeads with different functional groups were obtained from Polysciences
(Warmington, PA). Five $\mu$ l of beads were suspended in $1 \mathrm{ml}$ of HBSS, and $10 \mu \mathrm{l}$ of this suspension were added to the $50-\mu 1$ droplet containing hair cells. Under these conditions, approximately 1 to 8 beads randomly attached to each cell.

Cells were observed with a Leitz Fluovert inverted microscope and recorded through a Silicon Intensified Target video camera (SIT 66, DageMTI, Michigan City, IN) onto a SuperVHS recorder. The images were analyzed with a Quantex QX-7-210 image processing system (Quantex Corp., Sunnyvale, CA).

\section{Application of stimuli}

For $\mathrm{K}^{+}$-depolarization $(67 \mathrm{mM} \mathrm{KCl}$ final concentration), $50 \mu \mathrm{l}$ of a $140 \mathrm{mM} \mathrm{KCl-HBSS}$ solution $(\mathrm{NaCl}$ replaced by $\mathrm{KCl} ; 300 \pm 1 \mathrm{mOsm}$ ) were gently added with a pipette to the $60 \mu \mathrm{l}$ of HBSS containing the cells and the beads. For ionophore application, $10 \mathrm{mM}$ stock solutions of ionomycin

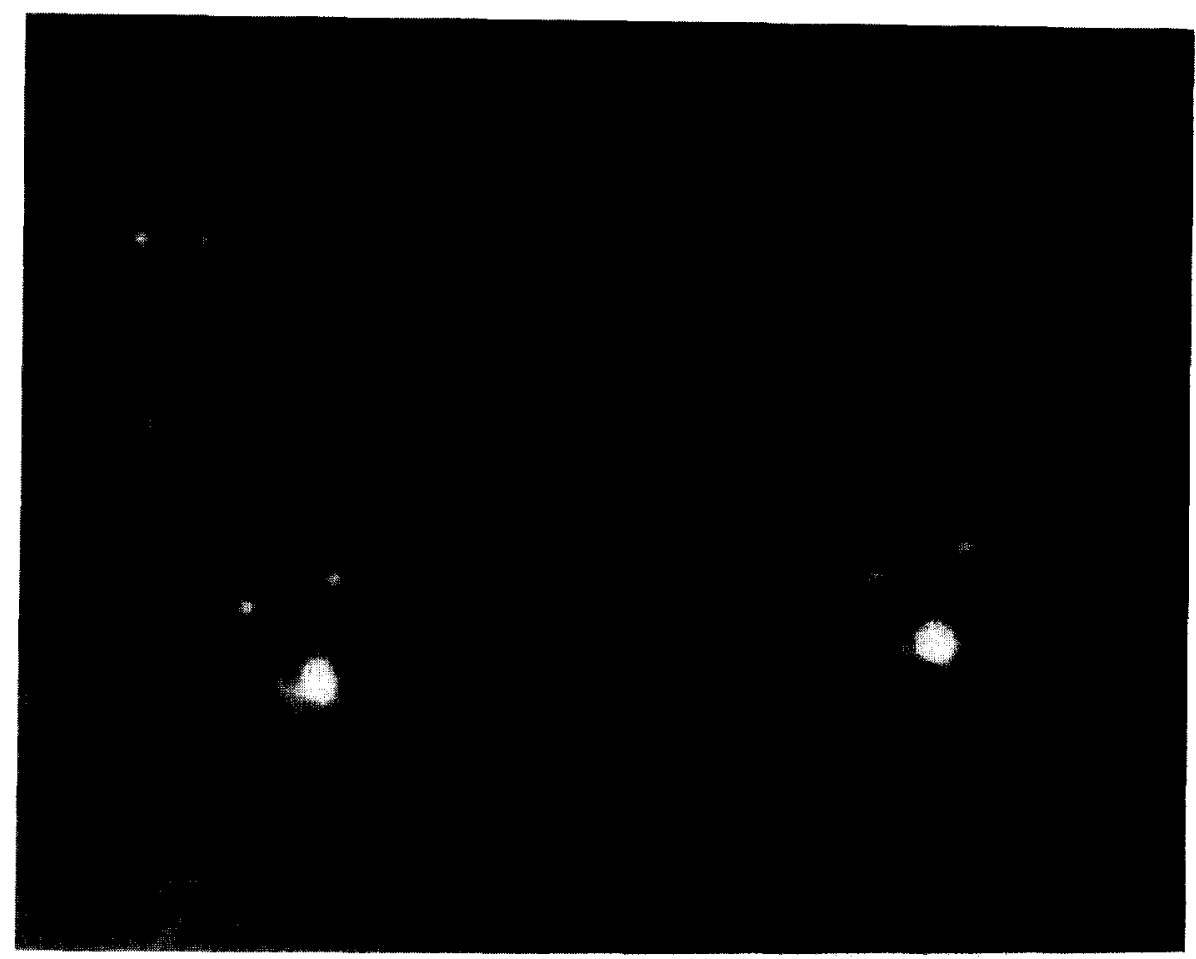

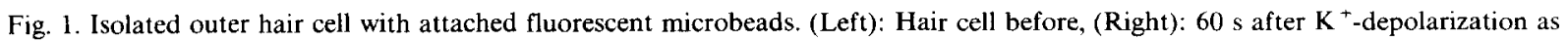
described in 'Methods'. For the overlay of bright-field images of hair cells and fluorescence of beads, the intensities of both light sources were adjusted while monitored on-line via the SIT video camera. 
(Calbiochem, La Jolla, CA) in dimethyl sulfoxide (DMSO) were added to the cells to a final concentration of $10 \mu \mathrm{M}$ ionomycin (final concentration of DMSO, 0.1\%).

\section{Results}

Microspheres exhibited somewhat different behavior depending on their functional groups. Carboxylate beads were selected over beads with amino- or hydroxy-functions since they dispersed better in HBSS and had no detrimental effects on cell viability. Most importantly, they bound well and did not change their position upon addition of HBSS. In any given experiment, one-third to one-half of the cells had at least three beads attached in a pattern that allowed measurements in various sections of the cell. On the remaining cells, beads were either too few or not distributed evenly. Fluorescence added to the ease of localization, and beads of $0.5 \mu \mathrm{m}$ diameter were readily resolved by the video system (Fig. 1).

Upon depolarization with $\mathrm{KCl}, 12$ out of 12 cells increased their diameter and volume and shortened their length in agreement with previous reports (Dulon et al., 1988). All cells shortened more in the middle region than in the apex, and 10 out of 12 also shortened more in the middle than in the base. The reduction in length ranged from $7.7 \%$ in the apical third to $13.9 \%$ in the middle (Table I). The overall shortening of $10 \%$ is comparable to previous accounts and indicates that the beads do not interfere with the movement of the hair cell.

TABLE I

LENGTH CHANGES OF ISOLATED OUTER HAIR CELLS

\begin{tabular}{lcc}
\hline Cell segment & \multicolumn{2}{l}{ Length (\% change) } \\
\cline { 2 - 3 } & $\mathrm{K}^{+}$-depolarization & Ionomycin \\
\hline Overall & $-10.0 \pm 5.0$ & $+6.8 \pm 2.9$ \\
Apex & $-7.7 \pm 6.8$ & $+5.9 \pm 1.9$ \\
Middle & $-13.9 \pm 5.9 *$ & $+6.4 \pm 3.1$ \\
Base & $-10.2 \pm 5.2$ & $+7.9 \pm 1.9 * *$ \\
\hline
\end{tabular}

Cells were isolated, stimulated, and analyzed as described in 'Methods'. Numbers are means \pm SD of measurements on 12 $\left(\mathrm{K}^{+}\right)$or 10 (ionomycin) different cells. ${ }^{*}$ differs from apex, $P<0.01$; from base, $P=0.02$ by paired $t$-test; * $*$ differs from apex, $P=0.06$ by paired $t$-test.
When intracellular calcium levels were increased by the application of ionomycin (Dulon et al., 1990), 10 out of 10 cells decreased their diameter and elongated. In 7 of the 10 cells the basal region elongated more than either the middle or the apical region. The elongation ranged from $5.9 \%$ in the apex to $7.9 \%$ in the base (Table I).

\section{Discussion}

Attaching microspheres to hair cells allows direct measurements of shape changes along any part of the cell body. The demonstration that such changes in response to chemical stimuli are not uniform along the cell axis underscores the usefulness of this approach in the elucidation of mechanisms of hair cell motility. It has been suggested that the $\mathrm{K}^{+}$-induced shortening is an osmotic swelling and not a 'contraction' in contrast to the $\mathrm{Ca}^{2+}$-mediated cortical contraction which leads to cell elongation (Dulon et al., 1988; Dulon et al. 1990). In the present study, the middle portion of the outer hair cell shortened significantly more than base or apex in $\mathrm{K}^{+}$-induced swelling. In $\mathrm{Ca}^{2+}$-induced elongation, we find a gradient along the cell axis with maximum elongation towards the base. This behavior clearly differentiates the mechanisms underlying these two phenomena from a simple reverse contraction/elongation.

Furthermore, the differential response along the cell axis after chemical stimulation contrasts with the pattern of length changes under electrical stimulation. In the latter case, relative displacement of points along the cell axis was the same regardless of the location of reference points ( $\mathrm{Hol}-$ ley and Ashmore, 1988). This differential response supports the view that different mechanisms underlie the 'fast' (electrically induced) and 'slow' $\left(\mathrm{Ca}^{2+}\right.$-induced) motility of outer hair cells.

In conclusion, the technique of measuring differential length changes along the cell body with attached microspheres provides an accurate means of delineating details of shape changes and contractile mechanisms in outer hair cells.

\section{Acknowledgement}

This work was supported by NIH Program Project Grant DC-00078. 


\section{References}

Brownell, W.E., Bader, C.R., Bertrand, D, and de Ribaupierre, Y. (1985) Evoked mechanical responses of isolated cochlear outer hair cells. Science 227, 194-196.

Dulon, D., Aran, J.M. and Schacht, J. (1988) Potassium-depolarization induces motility in isolated outer hair cells by an osmotic mechanism. Hear. Res. 32, 123-130.

Dulon, D., Zajic. G. and Schacht. J. (1990) Increasing intracellular free calcium induces circumferential contractions in isolated cochlear outer hair cells. J Neurosci. 10, 1399 _ 1397 ,

Dulon, D., Zajic, G, and Schacht, J. (1991) Differential motile response of isolated inner and outer hair cells to stimulation by potassium and calcium ions. Hear. Res. 53 (in press).

Goldstein, A.J. and Mizukoshi, O. (1967) Separation of the organ of Corti into its components. Ann. Otol. Rhinol. Laryngol. 76. 414-426.
Holley, M.C and Ashmore, J.F. (1988) On the mechanism of a high-frequency force generator in outer hair cells isolated from the guinea pig cochlea. Proc. R. Soc. Lond. 232 , $413-429$.

Slepecky. N.. Ulfendahl, M. and Flock, A. (1988) Effects of caffeine and tetracaine on outer hair cell shortening suggest intracellular calcium involvement. Hear. Res. 32, 11-22.

Warshaw, D., McBride, W. and Work. S. (1987) Corkscrew-like shortening in single smooth muscle cells. Science 236 , $1457-1459$

Zajic, G. and Schacht. I. (1987) Comparison of isolated outer hair cells from five mammalian species. Hear. Res. 26, 249-256.

Zenner, H.P., Zimmermann, U. and Schmitt, U. (1985) Reversible contraction of isolated mammalian cochlea hair cells. Hear. Res. 18, 127-133. 